\title{
Variabilidade genética em progênies de meios-irmãos de coentro ${ }^{1}$
}

\author{
Roberto de A Melo²; Dimas Menezes ${ }^{3}$; Luciane V Resende ${ }^{4}$; Luiz Jorge da G Wanderley Júnior ; Venézio \\ Felipe dos Santos ${ }^{6}$; Júlio Carlos P de Mesquita $^{6}$; Adriana G Magalhães ${ }^{3}$ \\ ${ }^{2}$ USP-ESALQ, Dep ${ }^{\text {to. }}$ Prod. Vegetal, C. Postal 09, 13418-900 Piracicaba-SP; ${ }^{3}$ UFRPE-Dep ${ }^{\text {to. }}$ Agronomia, Av. Dom Manoel de Medeiros, \\ s/n, 52171-900 Recife-PE; ${ }^{4}$ UFLA-Dep ${ }^{\text {to }}$ Agricultura, C. Postal 37, 37200-000 Lavras-MG; ${ }^{5}$ Hortivale, R. Valdomiro Rodrigues de \\ Andrade 103, Matriz, Vitória de Santo Antão-PE; 6IPA, Av. General San Martin, 1371, Bonji, Recife-PE; ramelo@esalq.usp.br; dimas@ \\ depa.ufrpe.br; luciane.vilela@dag.ufla.br; hortivale@uol.com.br; venezio@ipa.br; mesquitajulio@ibest.com.br; agmguedes@gmail.com
}

\section{RESUMO}

Grande número de produtores envolve-se com o cultivo do coentro durante todo o ano, tornando a cultura importante social e economicamente. Praticamente em toda a região Nordeste utiliza-se a cultivar Verdão. Estudos da variabilidade genética do coentro são importantes, tendo em vista o melhor planejamento de programas de melhoramento genético. Desta forma, este trabalho teve como objetivo quantificar a variabilidade genética de características agronômicas do coentro cultivar Verdão, avaliando-se progênies de meios-irmãos potencialmente úteis no melhoramento genético. O trabalho foi desenvolvido na Universidade Federal Rural de Pernambuco, em casa de vegetação, em blocos casualizados, com cinco repetições e parcelas de 28 plantas, colocadas em dois vasos. Os tratamentos foram compostos por 55 progênies de meios-irmãos da cultivar Verdão. O teste $\mathrm{t}$ detectou significância a 1 e a $5 \%$ de probabilidade entre as correlações genotípicas, fenotípicas e ambientais. A herdabilidade no sentido amplo variou de 7,19 (peso médio de plantas) a 81,09 (número de plantas pendoadas). Para a razão entre os coeficientes de variação genético e ambiental $\left(\mathrm{CV}_{\mathrm{g}} / \mathrm{CV}_{\mathrm{e}}\right)$, obteve-se de 0,27 (peso médio de plantas) a 2,07 (número de plantas pendoadas), indicando que a seleção contra o pendoamento apresenta as condições mais favoráveis em termos de ganhos genéticos imediatos. A correlação genotípica entre altura de plantas não pendoadas e número de plantas pendoadas foi alta e significativa.

Palavras-chave: Coriandrum sativum L., herdabilidade, correlação, características agronômicas.

\section{ABSTRACT}

\section{Genetic variability of half-sib progenies of coriander}

A large number of producers are involved in the cultivation of coriander throughout the year in Brazil, making it a crop of social and economic importance. Throughout nearly the entire Northeast Region, cultivar Verdão is used. Genetic variability studies on coriander are important for the proper planning of genetic improvement programs. The aim of the present study was to quantify the genetic variability for agronomic characteristics in cv. Verdão to contribute information toward genetic improvement. The study was developed at Universidade Federal Rural de Pernambuco, Pernambuco State, Brazil, in a greenhouse, using randomized blocks of 28 plants in two pots and five replications. The treatments were composed of 55 halfsib progenies from cultivar Verdão. The $t$ test detected significance at 1 and $5 \%$ likelihood between the genotypic, phenotypic and environmental correlations. Broad sense heritability ranged from 7.19 for average plant weight to 81.09 for number of bolted plants. The ratio between genetic and environmental coefficients of variation $\left(\mathrm{CV}_{\mathrm{g}} / \mathrm{CV}_{\mathrm{e}}\right)$ ranged from 0.27 (average weight) to 2.07 (number of bolted plants), indicating that selection against bolting presents more favorable conditions in terms of immediate genetic gains. The genotype correlation between height of non-bolted plants and the number of bolted plants was considered strong (0.86) and highly significant ( $\mathrm{t}$ test), enabling simultaneous gains from selection.

Keywords: Coriandrum sativum L., heritability, correlation, agronomic characteristics.

\section{(Recebido para publicação em 25 de março de 2009 aceito em 27 de agosto de 2009)}

\section{(Received in March 25, 2009; accepted in August 27, 2009)}

$\mathrm{O}$ coentro (Coriandrum sativum L., pertencente à família Apiácea, foi introduzido no Brasil no início da colonização, trazido pelos portugueses. Conhecido como planta aromática, medicinal e condimentar, é boa fonte de cálcio (188 mg $\left.100 \mathrm{~g}^{-1}\right)$, ferro (3 mg $\left.100 \mathrm{~g}^{-1}\right)$, vitamina C (75 mg $\left.100 \mathrm{~g}^{-1}\right) \mathrm{e}$ pró-vitamina A. Produz folhas e frutos muito aromáticos e por isso, é um dos temperos básicos para os pratos salgados da cozinha do Norte e Nordeste brasileiro, onde se utilizam as folhas frescas e os frutos inteiros ou moídos (Nascimento \& Pereira, 2005).

O coentro é cultivado por pequenos produtores e, também, em hortas domésticas, escolares e comunitárias, tanto para a produção de massa verde, comercializada em feiras livres e supermercados, como também para a produção de frutos, utilizados nas indústrias alimentícias e cosméticas (Oliveira et al., 2005). Praticamente em toda a região Nordeste utiliza-se a cultivar Verdão (Barros Júnior et al., 2004) e um grande número de produtores estão envolvidos com sua exploração durante todo o ano, tornando-a uma cultura de grande importância social e econômica.

Os resultados de pesquisa em coentro no Brasil referem-se mais à produção de massa verde (Alves et al., 2005; Oliveira et al., 2006), qualidade da semente (Pereira et al., 2005) e comparação entre genótipos (Barros Júnior et al., 2004; Oliveira et al., 2005). Poucos estudos têm sido desenvolvidos para o coentro nas áreas de nutrição mineral (Alves et

\footnotetext{
'Parte da dissertação de Mestrado em Agronomia do primeiro autor, na área de Melhoramento Genético de Plantas, pela Universidade Federal Rural de Pernambuco (UFRPE).
} 
al., 2005; Oliveira et al., 2006), transmissão de patógenos pelas sementes (Reis et al., 2006), desenvolvimento de novas cultivares (Pereira et al., 2005) e estudo da variabilidade genética (Melo, 2007).

O êxito do melhoramento genético está associado à capacidade de escolher os melhores indivíduos, que serão os genitores das próximas gerações (Cruz \& Carneiro, 2003). Uma das formas de identificar os melhores indivíduos é através do teste de progênie, definido por Allard (1971) como sendo a avaliação do genótipo dos genitores com base no fenótipo de seus descendentes. Segundo Farias Neto et al. (2005), progênies são entidades genéticas por meio das quais é possível estimar a variabilidade da população, bem como explicar a natureza da variação fenotípica. Para tanto, as características úteis ao melhoramento são avaliados nas progênies, geralmente testadas sob delineamentos experimentais.

Dentre os principais procedimentos para a estimação dos parâmetros genéticos em testes de progênies, destaca-se a análise de variância, cujos componentes são obtidos pela decomposição dos quadrados médios, com base nas suas esperanças matemáticas (Cruz \& Carneiro, 2003). Geralmente, os programas de melhoramento têm por finalidade obter cultivares aprimoradas para um conjunto de características. Por isso, o conhecimento da natureza e magnitude das correlações entre as características de interesse é de fundamental importância (Ferreira et al., 2003).

Estudos da variabilidade genética do coentro são importantes, tendo em vista o melhor planejamento de programas de melhoramento genético. Diversos trabalhos nesta linha têm sido realizados com diferentes espécies vegetais como, por exemplo, em milho (Paterniani \& Viégas, 1987; Carvalho et al., 2000; Ramalho et al., 2001), cebola (Buso, 1978; Candeia, 1984; Carvalho, 1996; Loges, 2001) e cenoura (Vieira et al., 2005; Alves et al., 2006; Vieira et al., 2006).

A cultivar Verdão, líder de mercado em todo o Brasil (Hortivale, 2007) e também em Pernambuco, é bastante precoce, com ciclo de 30 a 40 dias para a produção de folhas, dependendo da época do ano e da região. É bastante vigorosa, com folhas de coloração verde-escura, excelente rusticidade e boa resistência às doenças de folhagens. Os produtores, no entanto, reclamam da precocidade de espigamento e velocidade para florescimento, além de algumas plantas apresentarem partes roxas, em função da presença de antocianina.

Este trabalho teve como objetivo quantificar a variabilidade genética para características agronômicas existentes na cultivar Verdão, através da avaliação de progênies de meios-irmãos, visando o seu aproveitamento no melhoramento genético.

\section{MATERIAL E MÉTODOS}

O trabalho foi desenvolvido na Universidade Federal Rural de Pernambuco (UFRPE), em Recife-PE (8 ${ }^{\circ} 54^{\prime} 47^{\prime}$ 'S, $34^{\circ} 54^{\prime} 47^{\prime \prime} \mathrm{W}$, altitude de $6 \mathrm{~m}$ ), de 16 de novembro a 19 de dezembro de 2006, sob casa de vegetação com tela nas laterais e coberta com filme de polietileno transparente de 150 micras. O experimento foi conduzido em blocos casualizados, com cinco repetições, sendo as parcelas formadas por 28 plantas em dois vasos. Os tratamentos foram 55 progênies de meios-irmãos de coentro, cultivar Verdão.

Foram utilizados vasos de $2,8 \mathrm{~L}$, em um sistema hidropônico, tendo o pó de coco como substrato. Para melhorar a drenagem, colocou-se uma camada de brita na parte inferior do vaso e, sobre esta, uma tela de TNT (tecidonão-tecido), separando a brita do pó de coco. Foram semeadas sete covas por vaso, espaçadas de sete centímetros, formando um hexágono, com as sementes ocupando os vértices e o centro da figura. Colocou-se cinco sementes por cova, deixando-se, após o desbaste, 14 plantas por vaso. As fertirrigações foram feitas através de gotejamento, em todas as fases de desenvolvimento da planta, na frequência de uma a três vezes ao dia, dependendo da temperatura e da necessidade da cultura.

As médias mensais para temperatura máxima na cidade do Recife nos meses de novembro e dezembro foram, respec- tivamente, 31,3 e $31,5^{\circ} \mathrm{C}$, enquanto as médias das mínimas, para os mesmos meses, foram de 23,9 e 22, $0^{\circ} \mathrm{C}$ (Agritempo, 2007). As características analisadas foram número de plantas pendoadas (NPP), massa média das folhas (MMF), altura de plantas pendoadas (APP) e não pendoadas (APNP) e presença de antocianina (AN).

Todas as características foram avaliadas duas vezes, 27 e 34 dias após o semeio. A altura das plantas foi obtida no ponto de colheita, quando as plantas apresentavam o máximo desenvolvimento vegetativo, ou seja, no início do alongamento do caule, mas antes do pendoamento. Foi avaliado visualmente, atribuindo-se nota um para presença e nota zero para ausência de antocianina nas plantas. As avaliações foram finalizadas com a pesagem da parte aérea das plantas. Os dados obtidos de plantas individuais foram transformados para média da parcela e submetidos à análise de variância e covariância, utilizando-se o aplicativo computacional Genes-UFV (Cruz, 2001). Foram estimados os seguintes parâmetros, segundo a metodologia utilizada por Alves et al. (2006):

(1) Variância fenotípica entre médias de progênies: $\hat{\sigma}^{2} \mathbf{f}=(\mathrm{QMP} / \mathrm{r})$, em que: $\hat{\sigma}^{2} \mathbf{f}=$ variância fenotípica, $\mathbf{r}=$ repetições e $\mathrm{QMP}=$ quadrado médio das progênies;

(2) Variância ambiental média: $\hat{\sigma}^{2} \mathbf{e}=(\mathrm{QMR} / \mathrm{r})$, em que: $\hat{\sigma}^{2} \mathrm{e}=$ variância ambiental, $\mathrm{QMR}=$ quadrado médio do resíduo e $r=$ repetições;

(3) Variância genotípica entre médias de progênies: $\hat{\sigma}^{2} \mathbf{g}=(\mathrm{QMP}-\mathrm{QMR}) / \mathrm{r}$ , em que: $\hat{\sigma}^{2} \mathrm{~g}=$ variância genotípica, QMP $=$ quadrado médio das progênies, $\mathrm{QMR}=$ quadrado médio do resíduo e $\mathbf{r}=$ repetições;

(4) Herdabilidade no sentido amplo (baseada na média das parcelas): $\hat{h} a^{2}=\hat{\sigma}^{2} g / \hat{\sigma}^{2} f$, em que $\hat{h} a^{2}=$ herdabilidade no sentido amplo, $\hat{\sigma}^{2} \mathbf{g}=$ variância genotípica e $\hat{\sigma}^{2} \mathbf{f}=$ variância fenotípica;

(5) Coeficiente de variação genéti- 


$$
\text { ca: } C \hat{V} g=\left(\sqrt{\hat{s}^{2} g} / \hat{m}\right) \times 100 \text {, em que: }
$$

Ĉ̂g= coeficiente de variação genética, sendo igual à variância genotípica e corresponde à média geral do caráter;

(6) Correlações fenotípicas, em que: correlação fenotípica, PMPxy= produto médio das progênies/tratamentos, $\mathrm{QMPX}=$ quadrado médio do caráter $\mathrm{x}$ das progênies/tratamentos e QMPTy= quadrado médio progênies/tratamentos total;

(7) Correlações ambientais, em que: correlação ambiental, PMPxy= produto médio do resíduo, $\mathrm{QMRx}=$ quadrado médio do resíduo do caráter $X$ e $Q M R y=$ quadrado médio do resíduo do caráter $\mathrm{Y}$;

(8) Correlações genotípicas, em que: correlação genotípica, estimador da covariância genética das características $X$ e $Y$ e;

(9) $\mathrm{e}=$ estimadores da variância genéticas das características $\mathrm{X}$ e $\mathrm{Y}$, respectivamente.

$\mathrm{O}$ teste $\mathrm{t}$ foi aplicado a fim de se observar o nível de significância a 1 e $5 \%$.

\section{RESULTADOS E DISCUSSÃO}

A primeira avaliação, realizada aos 27 dias após o semeio, revelou que das 770 plantas mensuradas, 122 tinham iniciado o pendoamento, 14 plantas possuíam uma massa média de $82,46 \mathrm{~g}$ no ponto de colheita, o que por planta individual significa 5,89 g com 29,98 cm de altura. Já na segunda avaliação, das 742 plantas analisadas, 638 estavam pendoadas, com uma altura média de $40,50 \mathrm{~cm}$ uma vez que já tinham iniciado o processo de pendoamento e 408 plantas possuíam antocianina no pecíolo.

$\mathrm{Na}$ primeira avaliação, os valores para herdabilidade no sentido amplo $\left(\mathrm{h}_{\mathrm{a}}{ }^{2}\right)$ foram 30,77 e 81,09\% para altura de planta não pendoada e para número de plantas pendoadas respectivamente (Tabela 1). Na segunda avaliação os valores para herdabilidade foram 38,24, e $41,98 \%$ para presença de antocianina e número plantas pendoadas respectivamente (Tabela 1), indicando que essas características podem ser explorados pelo melhoramento, obtendo-se possíveis ganhos genéticos. Segundo Falconer (1987), a mais importante função da herdabilidade no estudo genético do caráter métrico é o seu papel preditivo expressando a confiança do valor fenotípico como um guia para o valor genético ou, em outras palavras, o grau de correspondência entre o valor fenotípico e o valor genético.

Segundo Vencovsky (1987), existe uma situação muito favorável para a obtenção de ganhos na seleção quando a relação $\mathrm{CV}_{\mathrm{g}} / \mathrm{CV}_{\mathrm{e}}$ tende a 1,0 ou maior que 1,0 já que, nesses casos, a variação genética supera a variação ambiental.

O valor mais elevado para a relação $\mathrm{CV}_{\mathrm{g}} / \mathrm{CV}_{\mathrm{e}}$ foi 2,07 (Tabela 1), encontrado para pendoamento, indicando que a seleção contra esse caráter apresenta as condições mais favoráveis em termos de ganhos genéticos imediatos. O pendoamento é uma característica indesejável na cultura do coentro para produção de folhagem. Após a planta iniciar o processo de pendoamento, todas as reservas vão sendo deslocadas para a formação do pendão floral, havendo uma redução no tamanho e qualidade das folhas. Em decorrência, torna-se importante a seleção de linhagens que produzam mais folhas em menos tempo e que possuam o início do processo de pendoamento mais tardio. Os programas de melhoramento devem focar a eliminação do pendoamento prematuro.

Os coeficientes de variação genéti$\cos \left(\mathrm{CV}_{\mathrm{g}}\right)$ para as características estudadas variaram de 4,08 a 54,62, para massa média das folhas e número de plantas pendoadas (Tabela 1), enquanto os coeficientes de variação ambiental $\left(\mathrm{CV}_{\mathrm{e}}\right)$ foram de 7,01 a 26,38, para altura de plantas não pendoadas e número de plantas pendoadas (Tabela 1), podendo ser considerados baixo para a maioria das características, o que comprova um bom controle ambiental e eficiência do delineamento experimental.

$\mathrm{O}$ alto valor para herdabilidade $\left(\mathrm{h}_{\mathrm{a}}{ }^{2}\right)$ observado para número de plantas não pendoadas sugere que essa característica pode ainda ser explorada em programas de melhoramento. As outras características apresentaram valores um pouco mais baixos para herdabilidade. Segundo
Ramalho et al. (2001), a herdabilidade pode ser considerada como o melhor parâmetro genético para se fazer qualquer inferência sobre o sucesso da seleção em um dado caráter.

Foram calculadas ainda as correlações genotípica, fenotípica e ambiental para as características avaliadas. Constatou-se que as correlações ambientais apresentaram valores inferiores a 0,45 , demonstrando que houve maior contribuição dos fatores genéticos nas correlações entre as características. A correlação genotípica entre altura de plantas não pendoadas, no ponto de colheita, e número de plantas pendoadas foi 0,86 , forte e significativa (teste $t$ ), podendo ser explorada pelo melhoramento, uma vez que o pendoamento precoce é uma característica indesejável nessa cultivar. Observou-se que as plantas mais baixas já tinham iniciado de pendoamento e consequentemente ocorreu uma diminuição no desenvolvimento foliar dessas plantas. Em contrapartida, as plantas que estavam no ponto de colheita, sem ter iniciado o pendoamento, exibiam folhagem bem desenvolvida, sendo por conseguinte mais altas. Os resultados positivos possibilitam ganhos simultâneos nas características correlacionadas. Nos períodos de temperatura elevada o pendoamento tem se expressado mais precocemente, acarretando prejuízos aos agricultores, uma vez que a qualidade do coentro e a produtividade ficam comprometidas.

Observou-se correlação positiva e mediana $(0,40)$, embora significativa, entre altura de plantas não pendoadas e peso médio de plantas, o que indica ainda haver ganhos genéticos possíveis em ambas as características na cultivar Verdão e que a seleção para uma das características pode resultar em ganhos genéticos na outra. Já a correlação entre número de plantas pendoadas e peso médio de plantas foi positiva e fraca $(0,22)$, possivelmente porque houve forte seleção para peso médio de plantas ao longo do programa de melhoramento de desenvolvimento da cultivar Verdão.

Na segunda avaliação, 34 dias após o semeio, a maioria das plantas já havia pendoado, possivelmente devido à temperatura elevada e, também, porque no sistema hidropônico é comum o ciclo 
Tabela 1. Estimativas de parâmetros genéticos para as características pendoamento, presença de antocianina, massa média das folhas e altura de plantas de 55 progênies de coentro obtidas a partir da cultivar Verdão (estimation of genetic parameters for bolting, presence of anthocyanin, and average weight of leaves average weight and height of plants of 55 coriander progenies, developed out of cultivar Verdão). Recife, UFRPE, 2006.

\begin{tabular}{|c|c|c|c|c|c|c|c|}
\hline \multirow{3}{*}{ Parâmetro genético } & \multicolumn{7}{|c|}{ Avaliação } \\
\hline & \multicolumn{3}{|c|}{12 de dezembro de 2006} & \multirow[b]{2}{*}{$\mathbf{A N}^{2}$} & \multicolumn{3}{|c|}{19 de dezembro de 2006} \\
\hline & $\mathbf{N P P}^{2}$ & MMF $^{2}$ & APNP $^{2}$ & & $\mathbf{N P P}^{2}$ & MMF $^{2}$ & $\mathbf{A P P}^{2}$ \\
\hline Variância fenotípica & 0,62 & 0,30 & 2,80 & 0,03 & 0,13 & 1,53 & 20,78 \\
\hline Variância ambiental & 0,02 & 0,12 & 0,87 & 0,00 & 0,02 & 1,10 & 6,06 \\
\hline Variância genética & 0,59 & 0,17 & 1,93 & 0,02 & 0,10 & 0,42 & 14,72 \\
\hline Herdabilidade $^{1}$ & 81,09 & 22,74 & 30,77 & 38,24 & 41,98 & 7,19 & 32,69 \\
\hline CV genético $\left(\mathrm{CV}_{\mathrm{g}}\right)$ & 54,62 & 7,17 & 4,63 & 15,87 & 9,37 & 4,08 & 9,64 \\
\hline $\mathrm{CV}$ ambiental $\left(\mathrm{CV}_{\mathrm{e}}\right)$ & 26,38 & 13,27 & 7,01 & 20,34 & 11,02 & 15,11 & 13,97 \\
\hline $\mathrm{CV}_{\mathrm{g}} / \mathrm{CV}_{\mathrm{e}}$ & 2,07 & 0,54 & 0,66 & 0,78 & 0,85 & 0,27 & 0,69 \\
\hline
\end{tabular}

${ }^{1}$ Herdabilidade no sentido amplo (broad-sense heritability); ${ }^{2} \mathrm{NPP}=$ número de plantas pendoadas (number of bolted plants); MMF $=$ massa média das folhas (average weight of leaves); APNP= altura de plantas não pendoadas (height of non-bolted plants); AN= presença de antocianina (presence of anthocyanin); APP $=$ altura de plantas pendoadas (height of bolted plants).

vegetativo ser menor. Já as correlações genotípicas entre altura de planta pendoada e antocianina e número de plantas pendoadas foram altas, positivas e significativas, com valores de 0,86 e 0,61 , respectivamente, o que permite afirmar que há ocorrência muito frequente de antocianina em plantas pendoadas. Segundo Diederichsen (1996), esta coloração estaria também ligada a algum fator de estresse, o que desencadearia o surgimento da antocianina na planta.

A presença de antocianina, em coentro, em determinadas regiões, é bem aceita pelo consumidor, já em outras não. Essa característica é bastante instável entre as cultivares presentes hoje no mercado brasileiro, uma vez que há variedades que apresentam maior concentração desse pigmento $\mathrm{e}$ no campo sempre aparecem plantas que não apresentam antocianina. Pode-se explorar essa característica no melhoramento genético e desenvolver uma cultivar que realmente seja mais rica e estável em antocianina e atender ao mercado consumidor que está sempre ávido por novidades.

No estudo de progênies de meiosirmãos da cultivar Verdão para características agronômicas constataram-se valores médios e altos de herdabilidade no sentido amplo e forte correlação genotípica entre algumas características possibilitando ganhos genéticos.

\section{AGRADECIMENTOS}

À HORTIVALE pelo fornecimento das sementes dos genótipos de coentro e parte dos equipamentos para realização dessa pesquisa.

\section{REFERÊNCIAS}

AGRITEMPO. 2007, 17 de abril. Sistema de Monitoramento Agrometeorológico. Disponível em www.agritempo.gov.br/ agroclima/sumário

ALLARD RW. 1971. Principios do melhoramento genético de plantas. São Paulo, 381p.

ALVES CS; PEIXOTO JR; VIEIRAJV; BOITEUX LS. 2006. Herdabilidade e correlações genotípicas entre caracteres de folhagem e sistema radicular em famílias de cenoura, cultivar Brasília. Horticultura Brasileira 24: 363-367.

ALVES EU; OLIVEIRAAP; ALCÂNTARA RL; SADER BR; ALVES AU. 2005. Rendimento e qualidade fisiológica de sementes de coentro cultivado com adubação orgânica e mineral. Revista Brasileira de Sementes 27: 132-137.

BARROS JÚNIOR AP; BEZERRA NETO F; NEGREIROS MZ; OLIVEIRA EQ; SILVEIRA LM; CÂMARA MJT. 2004. Desempenho agronômico de cultivares comerciais de coentro em cultivo solteiro sob condições de temperatura elevada e ampla luminosidade. Caatinga 17: 82-86.

BUSO JA. 1978. Estimativas de parâmetros genéticos de caracteres de planta e bulbo de cebola (Allium cepa L.). Piracicaba: USPESALQ. 132p (Tese mestrado).

CANDEIA J. 1984. Herdabilidade e correlações entre características em cebola (Allium cepa L.) $c v$. Piratropical. Botucatu: UNESP. 57p (Tese mestrado).

CARVALHO JF. 1996. Avaliação de progênies de meios-irmãos em cebola (Allium cepa L.) para caracteres fitotécnicos. Recife: UFRPE. 84p (Tese mestrado).

CARVALHO HWL; GUIMARÃES PEO; LEAL
MLSL; CARVALHO PCL; SANTOS MX. 2000. Avaliação de progênies de meios-irmãos da população de milho cms-453 no nordeste brasileiro. Pesquisa Agropecuária Brasileira 35: 1577-1584.

CRUZ CD. 2001. Programa Genes-Versão Windows: Aplicativo Computacional em Genética e Estatística. Viçosa: UFV. 648p.

CRUZ CD; CARNEIRO PCS. 2003. Modelos biométricos aplicados ao melhoramento genético. Viçosa: UFV. 585p.

DIEDERICHSENA. 1996. Coriander (Coriandrum sativum L.) Promoting the conservation and use of underutilized and negleted crops. 3. Rome: Institute of Plant Genetics and Crop Plant Research, Gatersleben/International Plant Genetic Resources Institute, 83 p.

FARIAS NETO JT; OLIVEIRA MSPO; MULLER AA; NOGUEIRA OL; ANAISSI DFSP. 2005. Variabilidade genética em progênies jovens de açaizeiro. Cerne 11: 336-341.

FALCONER DS. 1987. Introdução à genética quantitativa. Viçosa: UFV. 279p.

FERREIRA MAJF; QUEIROZ MA; BRAZ LT; VENCOVSKY R. 2003. Correlações genotípicas, fenotípicas e de ambiente entre dez caracteres de melancia e suas implicações para o melhoramento genético. Horticultura Brasileira 21: 438-441.

HORTIVALE. 2007, 17 de abril. Hortivale Sementes do Vale Ltda. Disponível em http:// www.hortivale.com.br

LOGES V. 2001. Variabilidade genética e correlações entre caracteres de cebola (Allium cepa L.) associados à resistência ao Thrips tabaci Lind. 1888 (Thysanoptera: Thripidae). Recife: UFRPE. 134p (Tese doutorado).

MELO RA. 2007. Caracterização morfológica e molecular em genótipos de coentro (Coriandrum Sativum L.) e estudo da viabilidade genética em progênies de meiosirmãos na cultivar Verdão. Recife: .UFRPE. 83p (Tese mestrado).

NASCIMENTO WM; PEREIRA RS. 2005. Coentro: a hortaliça de mil e uma utilidades. Horticultura Brasileira 23, n. 3. Nota de capa. 
OLIVEIRA AP; ALVES EU; ALCÂTARA RL; SADER BR; ALVES AU. 2006. Produção e qualidade fisiológica de sementes de coentro em função de doses de nitrogênio. Revista Brasileira de Sementes 28: 193-198.

OLIVEIRA EQ; BEZERRA NETO FB; NEGREIROS MZ; BARROS JÚNIOR AP; FREITAS KKC; SILVEIRA LM; LIMA JSS. 2005. Produção e valor agroeconômico no consórcio entre cultivares de coentro e de alface. Horticultura Brasileira 23: 285-289.

PATERNIANI E; VIÉGAS GP. Editores. 1987. Melhoramento e produção do milho. Campinas: Fundação Cargill. 795p.
PEREIRA RS; MUNIZ MFB; NASCIMENTO WM. 2005. Aspectos relacionados à qualidade de sementes de coentro. Horticultura Brasileira 23: 703-706.

RAMALHO AR; RAMALHO MAP; RIBEIRO PHE. 2001. Comportamento de famílias de meios-irmãos em diferentes épocas de semeadura visando à produção de forragem de milho. Ciência e Agrotecnologia 25: 510-518.

REIS A; SATELIS JF; PEREIRA RS; NASCIMENTO WM. 2006. Associação de Alternaria dauci e A. alternata com sementes de coentro e eficiência do tratamento químico. Horticultura Brasileira 24: 107-111.
VENCOVSKY R. 1987. Herança quantitativa. In: PATERNIANI E; VIEGAS GP (eds). Melhoramento e produção de milho. Campinas: Fundação Cargill. p. 137-214.

VIEIRA JV; CRUZ CD, NASCIMENTO WM; MIRANDA JEC. 2005. Seleção de progênies de meios-irmãos de cenoura baseada em características de sementes. Horticultura Brasileira 23: 44-47.

VIEIRA JV; NASCIMENTO WM; SILVA JB. 2006. Número mínimo de famílias de meiosirmãos para avaliação de uma população de cenoura. Pesquisa Agropecuária Brasileira 41: 365-367. 